Alfonso García Figueroa

«LA TESIS DEL CASO ESPECIAL
Y EL POSITIVISMO JURÍDICO»

DOXA 22 (1999) 


\title{
LA TESIS DEL CASO ESPECIAL Y EL POSITIVISMO JURÍDICO
}

\author{
Alfonso García Figueroa \\ Universidad de Castilla-La Mancha
}

\section{Introducción}

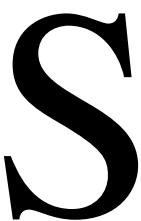

on ya más de veinte los años transcurridos desde la publicación de dos libros que nos han proporcionado una nueva visión de la interpretación y la aplicación del derecho: Theorie der juristischen Argumentation ${ }^{1}$ de Robert Alexy y Legal Reasoning and Legal Theory ${ }^{2}$ de D. Neil MacCormick. Estos trabajos representan el núcleo de lo que Atienza ha denominado «la teoría estándar de la argumentación jurídica» ${ }^{3}$. Pese a sus diferencias, estas obras ofrecen un planteamiento sustancialmente unitario, que gira en torno a la llamada «tesis del caso especial» (Sonderfallthese). La tesis del caso especial (en lo sucesivo TCE) suele expresarse del siguiente modo:

* Agradezco a los profesores Jerónimo Betegón, Marina Gascón, Luis Prieto y Santiago Sastre sus valiosas observaciones, sugerencias y objeciones a la primera versión de este trabajo. Mi agradecimiento se hace extensivo a los participantes en el IV Congreso Hispano-Italiano de Teoría del Derecho, celebrado en el Palacio de Valdeparaíso de Almagro (Ciudad Real) los días 8, 9 y 10 de octubre de 1998, por sus interesantes intervenciones en relación con la ponencia origen de este trabajo y en especial al profesor Fernando Atria, con quien he mantenido una estimulante correspondencia posterior sobre varios extremos de los aquí tratados. Obviamente, las posibles deficiencias de este trabajo en todos los órdenes son exclusiva responsabilidad de su autor.

${ }^{1}$ Alexy, R., Teoría de la argumentación jurídica (en los sucesivo TAJ) (1978), trad. de Manuel Atienza e Isabel Espejo, Centro de Estudios Constitucionales, Madrid, 1989 (esta edición incorpora un postfacio, «Respuesta a algunos críticos», págs. 289-318). Las obras de Aulis Aarnio y Aleksander Peczenik se inscriben en la misma línea de pensamiento que Alexy, como lo demuestra su colaboración en Aarnio, Alexy y Peczenik, «The Foundation of Legal Reasoning», en Rechtstheorie, nº12 (1981), págs. 133-158; 257-279; 423-448. Son especialmente destacables: en la obra de Aarnio, Lo racional como razonable, trad. de Ernesto Garzón Valdés, Centro de Estudios Constitucionales, Madrid, 1991 y en la de Peczenik, On Law and Reason, Kluwer, Dordrecht, 1989.

${ }^{2}$ MacCormick, N., Legal Reasoning and Legal Theory (en lo sucesivo LRLT) (1978), Clarendon Press, Oxford, 1997 (reimpr.).

3 Atienza, M., Las razones del derecho. Teorías de la argumentación jurídica, Centro de Estudios Constitucionales, Madrid, 1993, pág. 132. Para una visión general de las diversas teorías de la argumentación jurídica, también vide Neumann, U., Juristische Argumentationslehre, Wissenschaftliche Buchgesellschaft, Darmstadt, 1986. 
«El razonamiento jurídico es un caso especial del razonamiento práctico general» ${ }^{4}$

Desde luego, los autores citados no son los únicos que han sostenido este planteamiento. En realidad, es posible hallar mútiples formulaciones de esta idea básica. Por ejemplo, Nino expresaba esencialmente lo mismo cuando se refería a la «no fragmentación del discurso práctico» ${ }^{5}$, a la «no insularidad del discurso práctico» ${ }^{6} \mathrm{o}$ incluso al «carácter imperialista del discurso moral» ${ }^{7}$. Es más: la misma idea subyace en expresiones de uso común entre los juristas. Los jueces no sólo interpretan el derecho, sino que «hacen justicia conforme a derecho» ( $«$ do justice according to law» ${ }^{8}$ ) y hace poco tiempo no era difícil para los españoles imaginar a algún ex-Ministro de Justicia reclamando justicia frente a la decisión tomada por un Tribunal de Justicia ${ }^{9}$. En el lenguaje legal y en el cotidiano no se suele hablar del «titular de la cartera de la aplicación del derecho» para designar al Ministro de Justicia ${ }^{10}$ y a los Tribunales (que lo son de Justicia) no se les exige sólo decisiones jurídicas, sino decisiones justas ${ }^{11}$. Aparentemente, la convicción de que razonar según derecho es básicamente efectuar un juicio moral con ciertas particularidades forma parte de las creencias de los ciudadanos.

Durante estas dos décadas, la TCE ha originado un amplio desarrollo teórico, cuyos resultados y consecuencias se extienden sobre la teoría del

${ }^{4}$ MacCormick afirma que su teoría «presenta el razonamiento jurídico como una especie de razonamiento práctico» (LRLT, xii) y, en palabras de Alexy, «el discurso jurídico es un caso especial del discurso práctico general». Sin embargo, conviene aquí prescindir del término «discurso», que presenta unas connotaciones específicas en la teoría comunicativa, en favor del más neutral término «razonamiento».

5 Nino, C.S., Derecho, moral y política, Ariel, Barcelona, 1994, pág. 64.

${ }^{6}$ Nino, C.S., Derecho, moral y política, op. cit., págs. 79 ss.

7 Ibidem.

8 Vide LRLT, pág. 17.

9 Al momento de la presentación de esta ponencia, eran aún recientes un buen número de declaraciones a favor de los procesados y condenados Vera y Barrionuevo. Probablemente pocas veces la justicia haya sido invocada de manera tan próxima al emotivista golpe sobre la mesa al que se refirió Ross.

${ }^{10}$ Aunque por razones históricas no nos sorprenda, parece extraño que se designe un Ministerio asociándole a la virtud que idealmente debería satisfacer. Sin embargo, lo que nos parece familiar en el caso del Ministerio de Justicia, quizá lo sea menos en otros casos. Imaginemos, por ejemplo, que se le imputara a un Ministerio de la Fertilidad y la Abundancia Agropecuaria una irregular gestión de las ayudas comunitarias para el cultivo del lino y que el Ministro de la Elocuencia, como portavoz del Gobierno, desmintiera esas noticias ante una serie de periodistas.

${ }^{11}$ Recuérdese que nuestro Código Penal (art. 446) sanciona al juez que «a sabiendas, dictare sentencia o resolución injusta». Agradezco al profesor Pablo de Lora que me haya llamado la atención sobre este precepto para ilustrar la idea aquí apuntada. 
derecho. En realidad, a pesar de que la teoría de la argumentación jurídica no tiene por qué ser necesariamente incompatible con una visión positivista del derecho, la tesis del caso especial ha reforzado de manera más o menos consciente y explícita una teoría del derecho de corte no positivista, que viene disfrutando de una notoria hegemonía en los últimos tiempos. En este trabajo intentaré reconstruir la argumentación antipositivista que subyace a la tesis del caso especial y trataré de exponer algunas de las posibles objeciones que cabe plantear contra su pretendida virtualidad antipositivista.

\section{Algunas precisiones de la tesis del caso especial}

La TCE sin más especificaciones es ambigua y, por tanto, susceptible de diversas interpretaciones. Las siguientes son algunas de las precisiones que una teoría de la argumentación debe atender con el fin de restringir la ambigüedad de la TCE. Sin embargo, hay que lamentar que muy a menudo se invoca la TCE sin definir su significado preciso.

i) Contexto de descubrimiento/contexto de justificación ${ }^{12}$. El análisis que propone la teoría estándar de la argumentación jurídica se centra explícitamente en el contexto de justificación, no en el de descubrimiento ${ }^{13}$; es decir, en el conjunto de razones justificativas (jurídicas o no y explícitas o no) de la decisión jurídica y no en las causas psicológicas o sociológicas que la hayan propiciado. Éste es un avance considerable de la teoría estándar de la argumentación jurídica en relación con sus precursoras o con la teoría de la argumentación implícita en el realismo jurídico.

ii) Teoría del derecho. La teoría estándar de la argumentación jurídica se ocupa del razonamiento jurídico. Esto significa que la teoría de la argumentación presupone alguna teoría del derecho y singularmente alguna teoría acerca de las relaciones conceptuales entre derecho y moral. En palabras de MacCormick: «una teoría del razonamiento jurídico exige y es exigida por una teoría del derecho» ${ }^{14}$. Como he señalado, a pesar de que conceptualmente una teoría de la argumentación jurídica no es incompatible con una teoría positivista del derecho, de hecho la tesis del caso especial ha reforzado la vinculación conceptual de derecho y moral y, en este sentido, ha sido tendencialmente antipositivista. Este trabajo se centra específicamente en este aspecto de la tesis del caso especial.

\footnotetext{
${ }^{12}$ Como es sabido, la distinción se debe en estos términos a Hans Reichenbach (La filosofía científica, trad. de Horacio Flores Sánchez, Fondo de Cultura Económica, México D.F., 1967 (2 ed.), pág. 240). Sobre la relevancia jurídica de esta distinción, vide Gascón, M., Problemas de la fijación judicial de los hechos, McGraw-Hill, Madrid, en prensa.

13 Vide Atienza, M., Las razones del derecho, op. cit., págs. 22 ss., 134.

${ }^{14}$ LRLT, pág. 229.
} 
iii) Los agentes. Quienes desarrollan tal razonamiento jurídico y los ámbitos en los que tiene lugar pueden ser muy diversos. A la teoría de la argumentación jurídica le interesa especialmente el razonamiento jurídico de los órganos jurisdiccionales.

iv) Teoría descriptiva/teoría normativa. Aunque usualmente expuesta en términos aparentemente descriptivos, a veces no está del todo claro si la tesis del caso especial presenta un carácter descriptivo o bien normativo. En el primer caso, se afirma que el razonamiento jurídico es una clase de razonamiento moral; en el segundo, que el razonamiento jurídico debería ser una clase de razonamiento moral ${ }^{15}$. La adopción de una u otra perspectiva comporta consecuencias importantes. Esto no obstante, la teoría estándar de la argumentación a veces se muestra ambigua en este punto. Probablemente esta falta de claridad se halla vinculada a la indefinición del tipo de razonamiento práctico general referido en el propio enunciado de la tesis del caso especial. Por esta razón, el examen del carácter descriptivo o prescriptivo de la TCE (iv) será relacionado con el del tipo de razonamiento práctico general presupuesto en la TCE (infra vii).

v) La especialidad del razonamiento jurídico. Cuando se afirma que el razonamiento jurídico es un caso especial de razonamiento moral, se define el razonamiento jurídico per genus. Sin embargo, la especialidad del razonamiento jurídico respecto del práctico general parece una cuestión central en una interpretación acerca de la tesis del caso especial. Este carácter especial parece debilitar lo que sería una insostenible identificación de razonamiento jurídico y moral. Sin embargo, es dudoso que ni siquiera esta cautela sirva para contener las fuertes contradicciones que pueden llegar a generarse entre el razonamiento jurídico y el razonamiento moral (singularmente cuando se trata de un razonamiento moral correcto).

Quizá por eso, el positivismo tradicional ha tendido a concebir el razonamiento jurídico como una actividad plenamente autónoma respecto del razonamiento moral. Por su parte, el positivismo metodológico más moderno admite en principio la intervención de premisas morales en el razonamiento jurídico, pero con carácter excepcional (en los casos difíciles) en au-

${ }^{15}$ La perspectiva descriptiva puede ser a su vez escindida en dos partes. De este modo, Jerzy Wróblewski distingue hasta tres modelos de justificación: un modelo de justificación descriptivo, que simplemente muestra los argumentos de un área de razonamiento; un modelo de justificación descriptivo teórico, que reconstruye los argumentos de un razonamiento, como parte de una teoría argumentativa más amplia; finalmente, el modelo de justificación normativo indica qué argumentos se deben utilizar en la aplicación del derecho (Wróblewski, J., «Paradigms of Justifying Legal Decisions», en Peczenik, A, Lindahl, L., van Roermund, B. (eds.), Theory of Legal Science, Reidel, Dordrecht/Boston/Lancaster, 1984, págs. 253-273, aquí pág. 255). 
xilio de la justificación («interna» ${ }^{16} \mathrm{o}$ de «primer orden $»{ }^{17}$ ) basada exclusivamente en premisas jurídicas. En este sentido, la tesis del caso especial constituye en cierto modo una revolución frente a la visión tradicional de la aplicación del derecho. Según la TCE, el razonamiento jurídico es básicamente moral, pero se ve sometido a ciertos límites que lo especifican (la ley, el precedente, la dogmática y las reglas del ordenamiento procesal ${ }^{18}$ ).

vi) Punto de vista interno/punto de vista externo ${ }^{19}$. Esto no obstante, no nos hallamos en realidad ante un cambio revolucionario. Bajo la perspectiva de los juristas e incluso de los ciudadanos en general, el razonamiento jurídico ha sido a menudo considerado fundamentalmente moral. Como se ha señalado, los juristas hablan de «hacer justicia según derecho». Por tanto, la tesis del caso especial no constituye una teoría revolucionaria, sino, muy al contrario, simplemente la adopción del punto de vista tradicional de los participantes a la hora de analizar los procesos argumentativos en el ámbito del derecho. Tal punto de vista presenta un inconveniente fundamental: la indistinción de pertenencia y aplicabilidad, de teoría del derecho y teoría de la adjudicación, es decir, la imposibilidad de trazar los límites del derecho frente a otros órdenes normativos. Posteriormente insistiré en esta cuestión.

Antes de proseguir, cabe preguntarse cómo es posible que la tesis del caso especial presente a un tiempo una apariencia revolucionaria y tradicional. Creo que esta contradicción simplemente reproduce la que hallamos en la propia mentalidad de los juristas, escindida entre un positivismo teórico fiel al espíritu ultrarracionalista de la codificación y de la teoría formalista de la interpretación y, por otro lado, un iusnaturalismo legitimador de la propia actividad dogmática, legislativa y singularmente jurisdiccional. El positivismo teórico confía en la plenitud del sistema jurídico y por tanto excluye el recurso a elementos extrajurídicos en la aplicación del derecho. El iusnaturalismo vincula conceptualmente el derecho a la moral y, en consecuencia, la aplicación del derecho implica «hacer justicia conforme a derecho». El conflicto en la propia mentalidad del jurista tradicional explica que la TCE parezca revolucionaria y tradicional al mismo tiempo. En consecuencia, no es de extrañar que el punto de vista del participante, que es el punto de vista del jurista, suela proporcionar un concepto de derecho controvertido y confuso.

${ }^{16}$ Como es sabido, la distinción entre justificación interna y externa se debe, bajo esta terminología, a Jerzy Wróblewski («Legal Syllogism and Rationality of Judicial Decision», en Rechtstheorie, vol. 5 (1974), cuaderno 1/2, págs. 33-46).

17 Vide LRLT, págs. 19 ss.

18 Vide TAJ, págs. 36, 38.

${ }_{19}$ Sobre las implicaciones de una y otra perspectiva en una teoría del derecho, vide Sastre, S., Ciencia jurídica positivista y neoconstitucionalismo, McGraw-Hill, Madrid, 1999. 
vii) Moral crítica/social. Según la tesis del caso especial, el razonamiento jurídico es un caso especial de razonamiento moral, pero ¿en relación con qué moral? Como es sabido, la moral social se define como el conjunto de valores y pautas vigentes en una colectividad humana con independencia de su corrección y se opone a la moral crítica, racional, esclarecida, correcta con independencia de su aceptación social.

Nuevamente, la adopción de un punto de vista interno o externo es fundamental. Desde la perspectiva del observador externo, la moral a la que se vincula el razonamiento jurídico es una moral social, conforme o no con los dictados de la moral crítica. Bajo la perspectiva interna del participante, la moral a la que el razonamiento jurídico se vincula es la moral crítica, la moral correcta. Sin embargo, nada garantiza que el participante esté formulando una teoría ética racional. Esto significa que podemos distinguir entre moral social, moral crítica y moral crítica social, dependiendo del punto de vista que adoptemos ${ }^{20}$. Desde un punto de vista externo es posible indicar qué significa moral crítica y moral social. Desde la perspectiva del participante sólo es posible formular una moral crítica social. Con el sintagma «moral crítica social» me refiero al conjunto de pautas aceptadas como correctas por el participante. Si el participante formula un juicio moral puramente crítico, entonces está adoptando un punto de vista externo, porque no acepta $a$ priori la moral que evalúa. Si el participante formula un juicio moral puramente social (descriptivo), entonces también está adoptando un punto de vista externo, porque no acepta, sino que sólo describe una serie de prácticas. En ambos casos el participante deja de serlo genuinamente. Si en el Tercer Reich un sujeto cree que la política antisemita es correcta, entonces está formulando un juicio social en el sentido de que es conforme a una moral social vigente, pero al mismo tiempo es considerada correcta por el sujeto. La moral crítica social es objetivamente social, pero subjetivamente crítica.

En lo que sigue me referiré a las nociones de moral social y moral crítica siempre desde una perspectiva externa, salvo indicación contraria. Llamaré razonamiento moral social a la inferencia práctica, cuya premisa o premisas normativas fundamentales formen parte de la moral social y llamaré razonamiento moral crítico a la inferencia práctica, cuya premisa o premisas normativas fundamentales formen parte de la moral crítica.

viii) Teoría ética. La adopción de la TCE parece asentarse sobre algunos presupuestos en materia ética. La TCE presupone alguna teoría de éti-

${ }^{20}$ La distinción entre moral crítica y moral crítica social es análoga a la que Roscoe Pound establece entre un derecho natural natural («natural natural law») y un derecho natural positivo («positive natural law») (Pound, R., «Natural Natural Law and Positive Natural Law», en Law Quarterly Review, vol. 68 (1952), págs. 330-336). 
ca descriptiva en el caso de que se refiera al razonamiento moral social y presupone, según los casos, alguna teoría metaética descriptivista o alguna teoría de ética normativa cuando vincula el razonamiento jurídico al razonamiento moral crítico. No es casualidad que el desarrollo de la teoría de la argumentación coincida con la rehabilitación de la razón práctica.

ix) La cuestión de la única respuesta correcta. Finalmente cabría considerar si existe, como Dworkin sugiere ${ }^{21}$, una única respuesta correcta a nuestros interrogantes prácticos (y jurídicos en la medida en que la tesis del caso especial sea plausible). Alexy no comparte la tesis de la única respuesta correcta de Dworkin y mantiene, a cambio, «una versión débil de la tesis de la única respuesta correcta» ${ }^{22}$. Según el profesor de Kiel, cabe hablar no tanto de una única respuesta correcta, cuanto de un campo de posibilidad discursiva, que determina una serie de respuestas discursivamente correctas. Sin embargo, algunos autores ${ }^{23}$ han criticado esta debilitación de la tesis de la única respuesta correcta por parte de Alexy. Si existe un conjunto de diferentes respuestas igualmente correctas, entonces existe una pluralidad de sistemas de justificación igualmente correctos. En tal caso, puede que dos normas incompatibles sean igualmente correctas, lo cual, si bien es posible y más que probable en los casos de los sistemas jurídicos y de la moral social, no parece admisible cuando hablamos de moral crítica, de moral correcta, de moral racional.

\section{Cuatro interpretaciones de la tesis del caso especial}

Los expuestos son sólo algunos de los elementos para la reflexión que ofrece la teoría estándar de la argumentación jurídica y singularmente la TCE. Como señalé anteriormente, de entre las cuestiones planteadas, quizá dos merezcan un desarrollo conjunto y más detenido como punto de partida para un examen de la TCE y de sus implicaciones para el positivismo jurídico. Me refiero a la determinación del carácter descriptivo o normativo de la tesis del caso especial (iv) y, por otra parte, al tipo de razonamiento prác-

${ }^{21}$ Vide Dworkin, R., «¿Realmente no hay respuesta correcta en los casos difíciles?», trad. de Maribel Narváez, en Casanovas, P. y Moreso, J.J. (comps.), El ámbito de lo jurídico, Crítica, Barcelona, 1994, págs. 475-512.

${ }^{22}$ Alexy, R., «Sistema jurídico, principios jurídicos y razón práctica», trad. de Manuel Atienza, en Doxa, no 5 (1988), págs. 139-151, aquí pág. 140.

${ }_{23}$ Vide Bayón, J.C., La normatividad del derecho: deber jurídico y razones para la acción, Centro de Estudios Constitucionales, Madrid, 1991, pág. 258, nota 305; Summers, R.S., Comments on «The Foundation of Legal Reasoning», en Krawietz, W. y Alexy, R. (eds.), Metatheorie juristischer Argumentation, Duncker \& Humblot, Berlín, 1983, págs. 145-157, aquí pág. 155; Weinberger, O., «Der Streit um die praktische Vernunft. Gegen Scheinargumente in der praktische Philosophie», en Alexy, R. y Dreier, R. (eds.), Rechtssystem und praktische Vernunft, ARSP, cuaderno 51 (1993), Franz Steiner, Stuttgart, págs. 30-46, aquí pág. 43. 
tico que se considera general: la moral social o la moral crítica (vii). Si tomamos en consideración estas dos variables, entonces se presentan cuatro interpretaciones posibles de la tesis del caso especial, que involucran el resto de los elementos arriba indicados:

TCE1: El razonamiento jurídico es un caso especial de razonamiento moral social.

TCE2: El razonamiento jurídico debe ser un caso especial de razonamiento moral crítico.

TCE3: El razonamiento jurídico es un caso especial de razonamiento moral crítico.

TCE4: El razonamiento jurídico debe ser un caso especial de razonamiento moral social.

En lo que sigue me ocuparé de las tres primeras versiones de TCE. TCE4 no es relevante para los fines de este trabajo, pues simplemente formula desde una perspectiva externa la teoría de la interpretación que sostendría un participante fuertemente comprometido con la moral positiva. Se trata de la postura de un positivista ideológico.

\subsection{TCE1. El positivismo jurídico}

TCE1 expresa una tesis descriptiva relativa a la práctica forense formulada desde un punto de vista externo. Se trata de la constatación de elementos extrajurídicos relevantes en el razonamiento jurídico, cuya procedencia se halla básicamente en alguna forma de moral social.

En principio cabe asociar esta postura al positivismo jurídico. De acuerdo con éste, el derecho es producto de una serie de prácticas sociales (tesis de las fuentes sociale ${ }^{24}$ ) y es identificado por una regla maestra como la regla de reconocimiento hartiana, la norma básica de Kelsen o la «regla de identificación» ${ }^{25}$ de Bulygin. El derecho constituye, así pues, una obra de los hombres.

Toda obra humana es falible y el derecho lo es en dos aspectos muy relevantes: moral y técnicamente. El derecho es falible moralmente, porque sus respuestas pueden ser incompatibles con la moral crítica. El derecho es falible técnicamente en el sentido de que no siempre nos proporciona soluciones a los problemas que se le plantean. Es notorio que el derecho es impreciso lingüísticamente y presenta lagunas y antinomias. La constatación de la falibilidad moral del derecho se expresa en una de las tesis centrales

${ }^{24}$ Vide Raz, J., La autoridad del derecho, trad. de Rolando Tamayo y Salmorán, Universidad Autónoma de México, 1982, cap. III.

${ }^{25}$ Así denomina José Juan Moreso al criterio de validez positivista que formula Eugenio Bulygin en «Algunas consideraciones sobre los sistemas jurídicos», en Doxa, no 9 (1991), págs. 257-279, aquí págs. 263-4 (Moreso, J.J., La indeterminación del derecho y la interpretación de la Constitución, Centro de Estudios Políticos y Constitucionales, Madrid, 1997, pág. 148). 
del positivismo: la tesis de la separación de derecho y moral ${ }^{26}$. Se puede y se debe establecer los límites que separan las normas jurídicas de las normas morales, los usos sociales, etc. Por eso, Raz habla de la «tesis de los límites del derecho» ${ }^{27}$. Por su parte y desde la perspectiva del aplicador del derecho, la constatación de la falibilidad técnica del derecho da lugar a lo que Lyons ha denominado la «tesis del derecho limitado» ${ }^{28}$.

La tesis de los límites del derecho y la del derecho limitado son tesis independientes porque se puede sostener la tesis de los límites del derecho sin aceptar la tesis del derecho limitado. En tal caso nos hallamos ante un positivista teórico. En cierto modo, es el caso de Kelsen cuando sostiene la tesis de los límites del derecho (la norma básica determina qué es derecho y qué no es derecho), pero tal derecho no es tan limitado, en el sentido de que siempre proporciona una respuesta a las controversias jurídicas merced al principio de prohibición: todo lo que no está prohibido está permitido ${ }^{29}$.

También cabe la situación inversa: la de quien no acepta la tesis de los límites del derecho y sí la tesis del derecho limitado. En principio, la teoría de Alexy quizá pudiera ejemplificar esta situación, pues, en cuanto antipositivista, rechaza la tesis de los límites entre derecho y moral, pero no confía en que el derecho ni la moral a éste vinculada carezca de insuficiencias $\mathrm{y}$, en ese sentido, reconoce que el derecho es limitado (supra 1. ix).

Sin embargo, aquí me interesa destacar que la tesis de los límites del derecho y la tesis del derecho limitado normalmente presentan cierta complementariedad. Dado que el derecho presenta límites respecto a otros órdenes, podemos hallar en otros órdenes las soluciones que no nos proporciona el derecho limitado. Si el derecho presenta insuficiencias, entonces habremos de defender normalmente la tesis de la discreción judicial que impulsa al juez a buscar una solución en otros órdenes normativos. Si el derecho no

${ }^{26}$ Dada la perniciosa influencia de ciertas cuestiones puramente nominales en las disputas iusfilosóficas, quizá fuera mejor hablar de la tesis de la no vinculación de derecho y moral, en lugar de la tesis de la separación. A veces se ha interpretado equivocadamente al positivismo como la doctrina que separa el derecho de la moral, cuando lo único que afirma es que no se hallan necesariamente vinculados.

${ }_{27}$ Raz, J., «Legal Principles and the Limits of Law», en Yale Law Journal, vol. 81 (1972), págs. 823-854. Este trabajo fue parcialmente reimpreso acompañado de un postscriptum, en Cohen, M. (ed.), Ronald Dworkin and Contemporary Jurisprudence, Duckworth, Londres, 1984, págs. 73-87. Cito por esta última versión.

${ }^{28}$ Lyons, D., «Justification and Judicial Responsability», en California Law Review, vol. 72 (1984), págs. 178-199.

29 Vide Alchourrón,C.E. y Bulygin, E., Introducción a la metodología de las ciencias jurídicas y sociales, Astrea, Buenos Aires, 1987, págs. 184 ss. En tono crítico con la interpretación que los autores argentinos efectúan de la evolución del principio de prohibición en la teoría de Kelsen, vide Ruiz Manero, J., Jurisdicción y normas, Centro de Estudios Constitucionales, Madrid, 1990, págs. 42-45. 
proporciona una respuesta y el juez nunca se abstiene de emitir una resolución, entonces es necesario admitir que el juez ejerce cierta discreción.

En realidad, la tesis de la discreción presenta un aspecto descriptivo y un aspecto normativo. El aspecto descriptivo de la tesis de la discreción consiste simplemente en la constatación de que el sistema jurídico presenta insuficiencias que suelen ser colmadas por la actividad discrecional del juez basada en estándares morales sociales (TCE1). El aspecto normativo de la tesis de la discreción judicial expresa la conveniencia de que exista discreción judicial, formula un juicio positivo acerca de la necesidad de cierta discreción por parte de los operadores jurídicos ${ }^{30}$. Este aspecto normativo de la discreción judicial reclama alguna teoría de la argumentación jurídica que guíe al juez y presupone su conveniencia.

En suma, la discreción existe, es bueno que exista y podemos y debemos formular los mejores criterios posibles para ejercerla. En este sentido, el positivismo jurídico no sólo tolera una teoría de la argumentación jurídica, sino que la reclama y la valora. Tal modelo normativo de justificación podría expresarse de algún modo a través de TCE2. Sin embargo, antes de analizar esta posibilidad, podría aducirse contra esta armonía entre la TCE1 y el positivismo jurídico, que la doctrina positivista ha sido tradicionalmente reacia a admitir que siempre existan elementos de la moral social en la argumentación jurídica (TCE1) o que deban siempre estar presentes en alguna medida elementos de la moral crítica en la argumentación jurídica (TCE2).

En efecto, el positivismo teórico decimonónico concibió el razonamiento jurídico como completamente autónomo y autosuficiente, sin ningún punto de contacto con el razonamiento moral social o crítico. Sin embargo, este paleopositivismo ha perdido toda su vigencia. Por esta razón, más interés presenta la cuestión al referirla al modelo de interpretación implícito en las tesis hartianas. Da la impresión de que la tesis de la discreción presupone una estricta escisión de casos fáciles, donde el razonamiento jurídico se presenta como plenamente autosuficiente, y casos difíciles, donde el razonamiento moral actúa sin restricciones. Esta interpretación de la tesis de la discreción se funda sobre una falsa disyuntiva: sujeción al derecho o arbitrariedad. La crítica de Dworkin al positivismo jurídico presupone esta falsa disyuntiva ${ }^{31}$, pero el positivismo no afirma que el juez pueda simplemente imponer sus preferencias personales en los casos difíciles. El juez debe en todo caso justificar su decisión articulando una teoría de la argumentación jurídica.

${ }^{30}$ Vide, por ejemplo, Hart, H.L.A., El concepto de derecho (1961), trad. de Genaro Carrió,

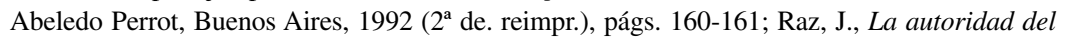
derecho, op. cit., pág. 99, nota 20; Ruiz Manero, J., Jurisdicción y normas, op. cit., pág. 185.

${ }^{31} \mathrm{Me}$ he referido a esta cuestión en mi trabajo Principios y positivismo jurídico, Centro de Estudios Políticos y Constitucionales, Madrid, 1998, págs. 270 ss. 
Por otra parte, el positivismo jurídico no tiene por qué negar que en el razonamiento jurídico de los casos fáciles pueden intervenir premisas morales de algún modo. La previa determinación de la facilidad o la dificultad de un caso se puede basar en consideraciones pragmáticas en las que pueden intervenir estándares de la moralidad social. Este planteamiento no afecta en nada a sus fundamentos ${ }^{32}$. La distinción de derecho y moral permite, precisamente, identificar los elementos del razonamiento jurídico que no son jurídicos.

En suma, TCE no se opone por tanto al positivismo jurídico, sino al holismo jurídico ${ }^{33}$. La necesidad de una teoría de la argumentación jurídica en principio surge como consecuencia de la insuficiencia del derecho para ofrecer por sí sólo respuestas a las controversias que se le presentan. Sólo un positivismo teórico estricto asociado a una teoría formalista de la interpretación excluye completamente la tesis del caso especial bajo todas sus versiones. También excluye la teoría de la argumentación jurídica.

\subsection{TCE2. La teoría de MacCormick}

TCE2 es una tesis normativa que prescribe la adecuación del razonamiento jurídico a la razón práctica. En este sentido, TCE2 es el complemento normativo de TCE1. TCE1 nos dice cómo es el razonamiento jurídico. TCE2 nos dice cómo debería ser.

La teoría de D.N. MacCormick pretende precisamente ofrecer una teoría normativa de la argumentación para orientar la discreción judicial. El propio MacCormick sugiere en el prólogo a Legal Reasoning and Legal Theory que, por diversas razones, este libro representa el complemento en el campo de la argumentación jurídica a la teoría del derecho positivista de

${ }^{32}$ La TCE deja abierta en principio la cuestión del concepto de derecho (positivista o no), si bien la adopción de una u otra versión de TCE puede ser más o menos compatible con ciertos conceptos de derecho en perjuicio de otros. Alexy afirma que existen al menos tres versiones de la TCE. Según la primera, que denomina «tesis de la secundariedad», el razonamiento jurídico es moral, pero posteriormente se le reviste con una «fachada jurídica». Según la que denomina «tesis de la adición», el razonamiento moral interviene cuando el jurídico es insuficiente y, finalmente, según la «tesis de la integración», los argumentos jurídicos y los morales interactúan en todos los niveles. Ésta es la interpretación de la TCE que defiende Alexy (TAJ, pág. 39). La tesis de la secundariedad parece propiciar una teoría realista o tópica del derecho. La tesis de la adición parece afín a la teoría de la interpretación del positivismo y finalmente, la tesis de la integración parece favorecer una concepción del «derecho como integridad» (Dworkin) o la articulación del derecho «desde su lado activo» (Alexy).

33 Vide Alexy, R., «Juristische Interpretation», en Recht, Vernunft, Diskurs, Suhrkamp, Francfort del Meno, 1995, págs. 71-92, aquí pág. 88: «el rival más importante de la tesis del caso especial es la idea del holismo jurídico». 
The Concept of Law de Hart ${ }^{34}$. Sin embargo, esta declaración de principios merece al menos dos precisiones.

La primera se refiere al carácter normativo de Legal Reasoning and Legal Theory. En realidad, la teoría de MacCormick no sólo ofrece criterios para saber cómo debemos argumentar, sino que pretende ser una descripción o una reconstrucción de la argumentación jurídica ${ }^{35}$ a partir de numerosas decisiones jurisdiccionales. El llamado «modelo de la aplicación racional del derecho (al que cabe adscribir a los autores de la teoría estándar de la argumentación jurídica) tiene una naturaleza mixta, pues puede ser interpretado como un modelo normativo, o como un modelo descriptivo o incluso ambas cosas a un tiempo» ${ }^{36}$.

Esta vía media que ensaya MacCormick presenta algunos riesgos de confusión entre discursos descriptivos y prescriptivos, aunque el propio autor se encarga de responder que «uno puede ser tanto censor como expositor sin confundir necesariamente ambos papeles» ${ }^{37}$. En realidad, la propensión hacia la falta de nitidez en la distinción de cuestiones descriptivas y prescriptivas es una muestra más del carácter marcadamente interno de la teoría de la argumentación jurídica. Los argumentos que presenta un participante básicamente coinciden con los que considera que debe presentar. Desde el momento en que no coincidan no estaremos ante un participante, sino ante un observador.

La segunda precisión presenta un carácter sobrevenido. En el citado prólogo a Legal Reasoning and Legal Theory, revisado en 1994, MacCormick pone de relieve que sus planteamientos inicialmente positivistas hartianos se han visto matizados en los últimos años ${ }^{38}$. En ese mismo prólogo el profesor escocés señala que Alexy y Habermas le han convencido de la vinculación entre la razón práctica discursiva y el razonamiento jurídico. Esto significa, en los términos de este trabajo, que la posición de MacCormick respecto a la TCE tiende a desplazarse desde TCE2 hacia TCE3.

No es el momento de referir los elementos esenciales de una obra ampliamente conocida ${ }^{39} \mathrm{ni}$ tampoco las transformaciones que haya podido ex-

${ }^{34}$ LRLT, pág. xiv.

${ }^{35}$ LRLT, pág. 13.

${ }^{36}$ Wróblewski, J., The Judicial Application of Law (editado por Zenon Bankowski y Neil MacCormick), Kluwer, Dordrecht, 1992, pág. 27.

${ }^{37}$ LRLT, pág. 77.

${ }^{38}$ LRLT, pág. xv. Vide MacCormick, N., «Law, Morality and Positivism», cap. VI de MacCormick, N. y Weinberger, O., An Institutional Theory of Law, trad. de los textos alemanes por Ruth Adler y Neil MacCormick, Reidel, Dordrecht, 1992 ( $2^{\mathrm{a}}$ ed.), especialmente págs. 139142. Sobre esta cuestión vide Ansuátegui Roig, F.J., El positivismo jurídico neoinstitucionalista, Dykinson, Madrid, 1996, págs. 78 ss.

${ }^{39}$ Vide Atienza, M., Las razones del derecho, op.cit., cap. quinto. 
perimentar en los últimos años. Baste recordar que la teoría de la argumentación de MacCormick reconoce el papel de la lógica deductiva en el razonamiento jurídico y propone una serie de argumentos fundamentales en los casos difíciles: los requisitos de consistencia y coherencia, los argumentos universalistas y los argumentos consecuencialistas. Sean cuales fueren los propósitos de la obra de MacCormick, es claro que sus planteamientos pueden ser aprovechados como una propuesta de modelo normativo que guíe la discreción judicial de los operadores jurídicos.

\subsection{TCE3. La teoría de Alexy}

TCE3 constituye la versión más fuerte de TCE. El razonamiento jurídico queda conceptualmente vinculado al razonamiento moral racional. La teoría de Alexy parece responder a esta interpretación de la TCE. Según Alexy, todo acto de habla normativo (y el razonamiento jurídico lo es) presenta una pretensión de corrección. En principio, desde la perspectiva del observador, una pretensión de corrección no puede garantizar más que una vinculación a la moral social ${ }^{40}$. La vinculación del razonamiento jurídico al correcto se basa en la adopción de un punto de vista interno para estudiar el derecho y la argumentación y en una serie de presupuestos trascendentales e hipótesis empíricas acerca de la naturaleza humana ${ }^{41}$. Veámoslo con algo más de detenimiento.

La teoría de Alexy adopta el punto de vista del participante, el punto de vista interno, para desarrollar su teoría del derecho y su teoría de la argumentación. Desde esta perspectiva, sería de algún modo contradictorio que un agente adoptara unos criterios jurídicos o morales que no fueran considerados por él mismo como correctos. En consecuencia, la tesis de la pretensión de corrección se asienta sobre este presupuesto: no es posible sostener ningún razonamiento normativo, justificatorio, sin considerarlo correcto. Constituiría una contradicción performativa argumentar en favor de una determinada postura práctica y considerarla al mismo tiempo incorrec-

${ }^{40}$ Quizá por esta razón Soper sostiene una tesis más débil, según la cual el derecho sólo presenta una «pretensión de aceptabilidad» que se basa en la buena fe de quien ejerce el poder, que lo hace coherente y sincero con sus propias creencias morales. Vide Soper, Ph., Una teoría del derecho, trad. de Ricardo Caracciolo con la colaboración de Silvia Vera, Centro de Estudios Constitucionales, Madrid, 1993, págs. 183 ss. Vide en tono crítico: Caracciolo, R., «L'argomento della credenza morale», trad. de Paolo Comanducci, en Comanducci, P. y Guastini, R. (comps.), Analisi e diritto 1994, Giappichelli, Turín, págs. 97-110, así como el trabajo sobre el referido libro de Soper por Luis Prieto en la Revista del Centro de Estudios Constitucionales, $\mathrm{n}^{\circ} 18$ (mayo-agosto 1994), págs. 233-242.

${ }^{41}$ Sobre la relevancia de este tipo de presupuestos, vide Betegón, J., «El concepto de persona en el debate entre liberales y comunitaristas», en Volubilis, nº 4 (octubre 1996), págs. 174187. 
ta. Se estaría haciendo algo contrario a lo que se está haciendo cuando se ejecuta el acto de habla. En este sentido, se afirma que todo razonamiento normativo incorpora una pretensión de corrección ${ }^{42}$.

Sin embargo, desde la perspectiva del observador externo cabe constatar dos problemas: primero, los individuos (entre los que se hallan legisladores y jueces) no son siempre coherentes con sus convicciones morales (en el caso de que las tengan) y, segundo, cuando lo son, no debemos olvidar que se trata tan sólo de eso: convicciones morales, no certezas morales, por así decir. Se trata, en los términos antes señalados, de una moral crítica social. El propio Alexy destaca que se trata de una mera pretensión de corrección. Un observador puede verificar sin grandes problemas que existen personas sin convicciones morales, personas incoherentes con sus propias convicciones morales y personas con convicciones morales incorrectas desde el punto de vista de la moral crítica. Lamentablemente, en el curso de la historia algunas personas como éstas han desarrollado (y aun hoy lo hacen) actividades legislativas, jurisdiccionales o dogmáticas. El mundo está lleno de personas con buenas intenciones, pero esto no parece impedir la existencia de órdenes normativos más o menos inicuos.

Frente a este tipo de inconvenientes, Alexy opone dos argumentos radicalmente distintos, uno de carácter pragmático trascendental y otro de naturaleza empírica. La primera cuestión es ¿por qué somos coherentes con nuestras convicciones morales? Según el argumento trascendental, la pretensión de corrección es una regla constitutiva de nuestros juegos de lenguaje. Si renunciamos a ella, no es que infrinjamos las normas de la comunicación; es que simplemente no estamos ejecutando un acto de habla válido, no estamos realizando un acto de comunicación, y si renunciamos siempre a hacer uso de las reglas constitutivas de la comunicación nos estamos autodestruyendo ${ }^{43}$. Alexy se inscribe de este modo en la tradición kantiana trascendental «ensanchada dialógicamente» ${ }^{44}$ por lo que hoy representa la teoría del discurso de K.O. Apel y Jürgen Habermas.

Queda entonces por solucionar un segundo interrogante: ¿qué garantiza que las convicciones morales de un individuo coincidan con los dictados de la moral crítica? En este punto, Alexy curiosamente adopta un aire entre intuicionista y utilitarista. Se muestra intuicionista porque el presupuesto de

${ }^{42}$ Vide una crítica a la tesis de la pretensión de corrección en Betegón, J., «Sobre la pretendida corrección de la pretensión de corrección», en Doxa, n 21 (1998), vol 1, págs. 171192.

${ }^{43}$ Vide Alexy, R., «Diskurstheorie und Menschenrechte», en Recht, Vernunft, Diskurs, op.cit., págs. 127-164, aquí pág. 139.

${ }^{44}$ La expresión es de Wellmer, A., Ética y diálogo. Elementos del juicio moral en Kant y en la ética del discurso, trad. de Fabio Morales, Anthropos, Barcelona, 1994, pág. 49. 
la coincidencia de las convicciones morales de los individuos con los dictados de la moral crítica parece presuponer que la bondad se halla de algún modo in cordibus scripta ${ }^{45}$. Se muestra utilitarista o hobbesiano ${ }^{46}$ porque viene a afirmar que cualquier individuo está interesado por motivos egoístas en la vigencia de las reglas morales implícitas en cualquier discurso normativo. La dimensión intuicionista de la teoría de Alexy pone al alcance de todos el conocimiento de la ética del discurso. La dimensión hobbesiana de la teoría de Alexy asegura el sometimiento de todos a la ética del discurso. En otras palabras, el aspecto intuicionista garantiza el entendimiento y el aspecto hobbesiano garantiza la voluntad. Ambas dimensiones de su teoría parecen entrar en conflicto con el planteamiento general de su obra, con el modelo racionalista kantiano que se halla en la base de la teoría ética de Alexy. Su racionalismo no se aviene con el intuicionismo moral ${ }^{47}$ y su deontologismo de raíz kantiana tampoco parece muy armónico con las consideraciones consecuencialistas.

No es posible profundizar aquí en la teoría de Alexy ${ }^{48}$. Basta para los propósitos de este trabajo poner de relieve algunos de sus inconvenientes más generales. La teoría de Alexy pretende crear un puente entre la tradición analítica y la hermenéutica, pero al grave precio de un uso inadecuado de ciertos instrumentos conceptuales aportados por la filosofía analítica ${ }^{49} \mathrm{y}$, sobre todo, mediante la adopción de un cúmulo de tesis débiles: una tesis débil de la vinculación de derecho y moral ${ }^{50}$, una tesis débil de la única respuesta correcta ${ }^{51}$ y una fundamentación pragmático trascendental débil ${ }^{52}$,

${ }^{45}$ El intuicionismo de Alexy se manifiesta en la vinculación entre el aspecto material y epistemológico de la corrección: «cuanto más extrema sea la injusticia, tanto más seguro su conocimiento» (Alexy, R., El concepto y la validez del derecho, trad. de Jorge M. Seña, Gedisa, Barcelona, 1994, pág. 57). También se percibe en su trabajo Mauerschützen. Zum Verhältnis von Recht, Moral und Strafbarkeit, Joachim Jungius, Hamburgo, 1993. Allí afirma que para determinar el umbral de injusticia que delimita en un sistema jurídico las normas extremadamente injustas (inválidas) de las no extremadamente injustas (que pueden ser válidas) hemos de atender a la evidencia de la injusticia.

${ }^{46} \mathrm{El}$ «argumento hobbesiano» de Alexy (vide TAJ, págs. 305-310) es prácticamente el mismo que aduce Soper bajo el nombre de «argumento utilitarista» (Soper, Ph., Una teoría del derecho, trad. de Ricardo Caracciolo, Centro de Estudios Constitucionales, 1993, págs. 103 ss. y 130 ss.).

${ }^{47}$ Vide TAJ, págs. 55-56.

${ }^{48}$ Vide Atienza, M., Las razones del derecho, op. cit., cap. sexto. Me he ocupado con cierto detenimiento de la teoría de Alexy en Principios y positivismo jurídico, op. cit., caps. quinto y sexto.

${ }^{49}$ En la medida en que Alexy se basa en la teoría de Habermas, vide el muy incisivo trabajo de Bar-Hillel, Y., «On Habermas' Hermenutic Philosophy of Language», en Synthese, ${ }^{\circ}$ 26 (1973), págs. 1-12.

${ }_{50}$ Vide Alexy, R., El concepto y la validez del derecho, op. cit., cap. primero.

${ }^{51}$ Supra 1.ix.

52 Vide Alexy, R., «Respuesta a algunos críticos», en TAJ, págs. 289-318, aquí pág. 306. 
que atraen sobre sí las objeciones de todas las tendencias a las que pretende satisfacer con su eclecticismo. Se trata de un «iusnaturalismo teñido lingüísticamente» ${ }^{53}$ y su éxito se explica, nos dice Weinberger, por una asociación de la teoría del discurso al ideario democrático, una vinculación sobrevalorada en Alemania ${ }^{54}$.

En lo que sigue me ocuparé básicamente de TCE3 por dos razones fundamentales: en primer lugar porque TCE3 parece haberse impuesto como la versión predominante de TCE y, en segundo, porque esta versión ha presentado una especial virtualidad antipositivista.

\subsubsection{TCE3 y el positivismo jurídico}

La TCE es una tesis acerca del razonamiento jurídico y el positivismo jurídico es un conjunto de tesis acerca del concepto de derecho. Se trata, por tanto, de cuestiones en principio distintas. Prueba de la neutralidad iusteórica de la teoría estándar de la argumentación jurídica es la distinta filiación de los dos máximos representantes de la teoría estándar de la argumentación jurídica: mientras que Alexy propugna una teoría del derecho no positivista, el MacCormick de Legal Reasoning sigue los pasos de H.L.A. Hart. Sin embargo, de hecho la TCE y, en general, la teoría de la argumentación jurídica han impulsado una teoría del derecho no positivista, es decir, han favorecido la vinculación conceptual necesaria de derecho y moral y quizá sea éste el origen de ciertas matizaciones que el positivismo de MacCormick haya debido formular en los últimos años. En la actualidad existen dos modos básicos de concebir la teoría de la argumentación jurídica: desde una perspectiva positivista según la articulación de TCE1 y TCE2 y desde una perspectiva no positivista a partir de TCE3, que será analizada a continuación.

La virtualidad antipositivista de TCE3 se basa en que los juristas «hacen justicia según derecho» y esto significa que el juez hace siempre justicia en alguna medida cuando aplica el derecho y que siempre aplica el derecho en alguna medida cuando imparte justicia.

La afirmación de que el juez hace justicia cuando aplica el derecho entra en conflicto con la tesis positivista de la separación de moral y derecho, en cuanto que presupone con carácter necesario lo que el positivismo considera contingente: cierta corrección moral en las premisas normativas (entre ellas las jurídicas) del razonamiento jurídico. La afirmación de que el

53 «Linguistisch gefärbtes Naturrecht», en palabras de Hilgendorf («Zur traszendentalpragmatischen Begründung von Diskursregeln», en Rechtstheorie, nº 27 (1995), págs. 183200, aquí pág. 199).

${ }^{54}$ Vide Bulygin, E., «Entrevista con Ota Weinberger», en Doxa, nº 11 (1992), págs. 313323. 
juez aplica el derecho al impartir justicia afecta a las tesis positivistas de los límites del derecho y, en consecuencia, afecta a la tesis del derecho limitado y a la tesis de la discreción judicial. La condición de «caso especial» del razonamiento jurídico en TCE3 sirve para matizar estas consecuencias extremadas, pero creo que no es una cautela satisfactoria. Veamos estas cuestiones con más detenimiento.

\subsubsection{TCE3 y la tesis de la separación: ¿hace el juez justicia cuando aplica el derecho?}

Cuando se afirma que el razonamiento jurídico es un caso especial de razonamiento moral, se define al razonamiento per genus y al mismo tiempo se presuponen algunas diferencias que lo especifican. Por lo tanto, el razonamiento jurídico es caracterizado como una clase que mantiene una relación de inclusión con la clase razonamiento práctico. Esto significa que la clase razonamiento jurídico pertenece a la clase del razonamiento práctico, de mayor extensión. La cuestión es entonces qué propiedad o propiedades definen la clase razonamiento práctico y bajo cuáles cabe admitir o no al razonamiento jurídico.

Los miembros de la clase razonamiento práctico tienen la propiedad de ser una inferencia en la que figura al menos una norma. Admitir que el razonamiento jurídico es un caso especial de razonamiento práctico en este sentido sería trivial. En realidad no tendría sentido ni siquiera hablar del razonamiento jurídico como un caso especial. Se trataría de un caso más de razonamiento práctico ${ }^{55}$. Sin embargo, en TCE3 se habla de un razonamiento práctico basado en los dictados de la moral correcta. La propia idea de «hacer justicia según derecho» presupone que debe existir cierta coherencia entre el derecho y la moral. ¿Sería acaso posible hacer justicia según derecho injusto? ¿Sería posible razonar moralmente con premisas jurídicas inmorales? Parece que si admitimos la posibilidad de un derecho injusto, entonces es difícil aceptar abiertamente TCE3.

Así las cosas, los defensores de TCE3 pueden introducir la cautela de la especialidad. En realidad, TCE habla de caso especial para excluir la identidad de razonamiento jurídico y razonamiento moral. Esta matización desarrolla una función análoga a la del carácter extremadamente injusto de las normas que no pueden pertenecer al derecho según el argumento de la injusticia de la célebre fórmula de Radbruch ${ }^{56}$. Es más, TCE3 no sólo presen-

\footnotetext{
${ }_{55}$ Prescindiendo de la cuestión de que algunos razonamientos jurídicos no siempre presentan un carácter normativo, dada la existencia en los sistemas jurídicos de, por ejemplo, definiciones.

${ }^{56}$ Sobre este argumento, vide Alexy, R., El concepto y la validez del derecho, op.cit., pág. 34; Radbruch, G., Filosofía del derecho, Revista de Derecho Privado, Madrid, 1959.
} 
ta esta analogía con el argumento de la injusticia. En realidad TCE3 y el argumento de la injusticia resultan complementarios. Veamos en qué sentido.

Como es sabido, según la fórmula de Radbruch, las normas extremadamente injustas no pertenecen al derecho. De este modo, es posible admitir que existen normas injustas, pero no extremadamente injustas, en cualquier ordenamiento jurídico. Se trata de una corrección del iusnaturalismo tradicional, por la que el derecho deja de ser justo ex definitione. Como bien dice Peczenik, hemos pasado del «lex iniusta non est lex» al «lex iniustissima non est lex» ${ }^{57}$. Ésta es, nos dice Alexy, «la gracia (Witz) de la fórmula de Radbruch» ${ }^{58}$. Si el problema en teoría del derecho es entonces cómo determinar el «umbral de la injusticia» («Unrechtsschwelle») que separa lo injusto de lo extremadamente injusto, análogamente el problema en teoría de la argumentación reside en cómo determinar el límite a la especialidad, es decir, dónde situar el umbral que define el grado de tolerancia máxima de premisas injustas en el razonamiento práctico. Ésta es una cuestión no suficientemente aclarada por la teoría de la argumentación jurídica. Probablemente, esto se explique mejor por la complementariedad de TCE3 y una concepción no positivista del derecho. Si mantenemos una concepción no positivista del derecho, entonces no pueden darse premisas jurídicas extremadamente injustas en el razonamiento jurídico (pues las normas extremadamente injustas no serían jurídicas), lo que elimina la ocasión para que se produzcan contradicciones extremas entre las premisas jurídicas y el razonamiento moral crítico. De este modo se elimina el problema y además resulta innecesario referirse a él.

Volviendo al núcleo de la argumentación, TCE3 entonces sólo puede sostenerse sobre alguna de estas dos posibilidades: a) establecer la corrección moral en términos puramente formales, procedimentales o b) restringir la extensión de los razonamientos jurídicos y limitarla a aquéllos que proporcionan premisas adecuadas para un razonamiento moral correcto. Ambas estrategias aparecen de manera recurrente en las argumentaciones de numerosos teóricos.

a) La teoría de Alexy parece concebir el razonamiento práctico en términos extremadamente formales, procedimentales ${ }^{59}$, y en ocasiones llega a

${ }^{57}$ Peczenik, A., «Dimensiones morales del derecho», trad. de Juan A. Pérez Lledó, en Doxa, no 8 (1990), págs. 89-109, aquí pág. 104.

${ }_{58}$ Alexy, R., Mauerschützen. Zum Verhältnis von Recht, Moral und Strafbarkeit, op. cit., pág. 33.

${ }_{59}$ El carácter intrínsecamente procedimental de la ética del discurso unido a la superioridad procedimental que exhibe el derecho frente a las incertidumbres que plantea con frecuencia la moral ha contribuido a concebir la moral como «una forma deficiente de derecho», como advierte Cortina, A., «La moral como forma deficiente de derecho», en Doxa, $\mathrm{n}^{\circ} 5$ (1988), págs. 69-85. 
vaciar de contenido la propia idea de moral $^{60}$, lo que abre la extensión de los razonamientos prácticos a cualquier razonamiento normativo, a cualquier acto de habla normativo. Este planteamiento no es nuevo ni tampoco es exclusivo de la teoría de la argumentación jurídica en el actual panorama iusfilosófico. Veámoslo con más detenimiento.

$\mathrm{El}$ argumento no es nuevo. En ocasiones se ha afirmado del derecho que es «estructuralmente moral». Aranguren caracteriza del siguiente modo la idea de «moral como estructura»:

«Desde hace mucho tiempo he desarrollado la distinción, procedente de Xavier Zubiri, entre moral como estructura y moral como contenido. El hombre, por "inmoral" que en cuanto al contenido de su comportamiento pueda, en ocasiones, ser, es siempre moral en cuanto que, inexorablemente, le compete el "quehacer" de su vida (incluida la forma, deficiente por donde quiera que se la mire, de dejar que se la hagan los demás). El hombre, personal y socialmente considerado, es el actor, el agente y el autor de su vida: representa un papel -o muchos- con el cual actúa sobre la realidad, siguiendo el hilo de su propia invención. Naturalmente, no se inventa arbitrariamente una forma de vida, ni ésta incide caprichosamente sobre la realidad, ni la representación se lleva a cabo en la pura improvisación, sino que es sobre la base de unos condicionamientos (...) como se hacen el hombre y la sociedad.» ${ }^{61}$

Bajo este punto de vista, la moral es considerada simplemente como un sistema más o menos consistente de pautas que guían con más o menos regularidad la conducta de un individuo y que suelen tener su origen en la propia moral social. En consecuencia, sea cual fuere la conducta voluntaria de un individuo, será considerada «estructuralmente moral» según este planteamiento. En este sentido, decir que el derecho o el razonamiento jurídico es «estructuralmente moral» es prácticamente trivial.

Por otra parte, en la actualidad el argumento no es exclusivo de la teoría de la argumentación jurídica. La estrategia de la teoría de las razones para la acción ${ }^{62}$ sigue unos pasos semejantes a la teoría de la argumentación jurídica. De hecho, TCE3 parece un presupuesto de la teoría de las razones para la acción. El razonamiento jurídico es considerado como parte de un discurso más amplio unificado por la idea de justificación, que en último término debe ser de carácter moral, pero esto sólo puede tener lugar me-

${ }^{60}$ Vide Prieto, L., Ley, principios, derechos, Dykinson, Madrid, 1998, pág. 67.

${ }^{61}$ Aranguren, J.L.L., Ética de la felicidad y otros lenguajes, Tecnos, Madrid, 1992 (2 ${ }^{\mathrm{a}}$ de.), pág. 110. Allí se remite a su obra Ética, Revista de Occidente, Madrid, 1960.Vide sobre la noción de moral como estructura Fernández García, E., Estudios de ética jurídica, Debate, Madrid, 1990, cap. 5 y Hermida del Llano, C., J.L.L. Aranguren (1909-1996), Ediciones del Orto, Madrid, 1997, págs. 28 ss.

${ }^{62}$ Vide sobre esta cuestión: Raz, J., Razón práctica y normas, trad. de Juan Ruiz Manero, Centro de Estudios Constitucionales, Madrid, 1991; Bayón, J.C., La normatividad del derecho: deber jurídico y razones para la acción, op. cit. 
diante una consideración meramente «estructural» (es decir, vacía) de la moral. Cristina Redondo lo expresa del siguiente modo:

«La única forma de llegar a la moral como patrón unificador del razonamiento del individuo es vaciándola de contenido (...) El problema es que bajo esta interpretación la palabra «moral» está desprovista de todo contenido, y su utilización se explica sólo por el efecto emocional positivo que conserva» ${ }^{63}$

b) Pero también se ha recurrido a menudo a la segunda estrategia, es decir, restringir la extensión del concepto de derecho, tomando como central el caso del razonamiento jurídico en los Estados de derecho constitucionales occidentales y manteniendo una teoría del derecho no positivista que no tolera en la extensión del concepto de sistema jurídico el derecho injusto, lo que impide la presencia de premisas normativas injustas, contrarias a la corrección del razonamiento práctico, como ya he señalado anteriormente. Esta vía (la vía de cierto constitucionalismo ${ }^{64}$ ) ha gozado de particular éxito entre «filósofos del derecho con vocación de constitucionalistas y de constitucionalistas con vocación de filósofos del derecho» ${ }^{65}$ (entre los primeros se incluirían Alexy, Dworkin, Habermas o Nino y entre los segundos Gustavo Zagrebelsky ${ }^{66}$ ).

No es posible entrar a fondo en esta cuestión. Sin embargo, cabe al menos señalar algunas precisiones. En principio, ambas estrategias son legítimas. En un discurso puramente estipulativo, podemos establecer las definiciones que más nos convengan y eliminar los inconvenientes ex vi terminorum. Sin embargo, desde un metadiscurso analítico y un metadiscurso normativo, esta opción presenta algunos problemas. Desde un metadiscurso analítico, este planteamiento plantea más riesgos de confusión e incorpora cuestiones metaéticas que resolver de gran dificultad (¿qué significa «justicia»? ¿dónde se halla el límite de lo justo, lo injusto y lo extremadamente

${ }^{63}$ Redondo, M.C., La noción de razón para la acción en el análisis jurídico, Centro de Estudios Constitucionales, Madrid, 1996, pág. 243.

${ }^{64}$ Vide Prieto, L., Constitucionalismo y positivismo, Fontamara, México, 1997. He escrito un comentario a esta obra en Revista Española de Derecho Constitucional, $\mathrm{n}^{\circ} 54$ (1998), págs. 367-381.

${ }^{65}$ Prieto, L., «La doctrina del derecho natural», en Betegón, J., Gascón, M., Páramo, J.R. de, Prieto, L., Lecciones de teoría del derecho, McGraw-Hill, Madrid, 1997, págs. 31-66, aquí pág. 65.

${ }^{66}$ Vide Zagrebelsky, G., El derecho dúctil, trad. de Marina Gascón, Trotta, Madrid, 1995; Peces-Barba, G., «Desacuerdos y acuerdos con una obra importante», epílogo a la primera edición de El derecho dúctil, op. cit., págs. 157-173; Ansuátegui, F.J., «¿Crisis del positivismo jurídico? Dos respuestas italianas: Zagrebelsky y Scarpelli», en Derechos y Libertades, ${ }^{\circ} 2$ (1994), págs. 113-151; Guastini, R., «Diritto mite, diritto incerto», en Materiali per una storia della cultura giuridica, $\mathrm{n}^{\circ} 2$ (diciembre 1996), págs. 513-525. Vide también los trabajos a propósito de la obra de Zagrebelsky en Anuario de Filosofía del Derecho (1996-1997). 
injusto? etc.). Desde un metadiscurso normativo, la estipulación no positivista comporta la devaluación de la moral crítica.

La saludable relativización de la polémica en términos de meras estipulaciones lingüísticas sobre la base del carácter intrínsecamente convencional del lenguaje nos debería conducir a la siguiente afirmación de Waismann: «nuestra perspectiva es sólo la mejor, cuando las demás nos engañan» ${ }^{67}$. Se trata, por tanto, de determinar un concepto de derecho lo menos engañoso posible desde un metadiscurso analítico y un metadiscurso normativo. En este sentido, aquí se sostiene que el positivismo sigue siendo la opción mejor.

En suma, regresando al núcleo de este trabajo, si se caracteriza el razonamiento práctico materialmente, como el conjunto de inferencias normativas sustantivamente correctas y/o si entendemos por derecho no sólo el conjunto de sistemas jurídicos propios de los Estados de derecho constitucionales, entonces el razonamiento jurídico, vinculado a una serie de normas jurídicas que son justas sólo de manera contingente, puede entrar en conflicto con el razonamiento práctico general. Bajo este punto de vista, como señala Braun, quizá la argumentación jurídica no sea un minus, sino un alliud con respecto a la argumentación moral ${ }^{68}$.

2.3.1.2. TCE3 y la tesis de los límites del derecho: ¿aplica el juez derecho cuando imparte justicia?

Hasta el momento me he referido a los problemas que se derivan de la moralización del razonamiento jurídico en TCE3. A continuación, me ocuparé de la cuestión de la juridificación del razonamiento moral. La cuestión es: ¿aplica el juez invariablemente derecho cuando hace justicia?

Normalmente, el principio de legalidad somete la actividad jurisdiccional al derecho. En rigor, el juez debe aplicar el derecho y solamente el derecho. Sin embargo, del análisis de la fundamentación de las decisiones judiciales se desprende que en éstas no sólo figuran normas jurídicas, sino que podemos hallar consideraciones de justicia, referencias a la moral social o condicionamientos ideológicos. La cuestión es, como afirman Coval y Smith, que «la riqueza del output no puede ser explicada con tal pobreza de input» ${ }^{69}$.

Para explicar la riqueza del output caben sendas interpretaciones: la interpretación positivista y la no positivista. Según el positivismo, el juez apli-

\footnotetext{
${ }^{67}$ Waismann, F., Los principios de la filosofía lingüística, trad. de José Antonio Robles, UNAM, México, 1970, pág. 53.

${ }^{68}$ Braun, C., «Diskurstheoretische Normenbegründung in der Rechtswissenschaft», en Rechtstheorie, nº 19 (1988), págs. 238-261, aquí pág. 259.

${ }^{69}$ Coval, S.C. y Smith, J.C., «Some Structural Properties of Legal Decisions», en Cambrigde Law Journal, nº 32 (1) (abril, 1973), págs. 81-103, aquí pág. 81.
} 
ca el derecho y ejerce además cierta discreción judicial. La explicación positivista consiste en que al input inicial se le han añadido otros elementos. Según el no positivismo, en cambio, el sistema jurídico no era tan restringido como había sostenido el positivismo. La explicación es en este caso que el input era mayor de lo que el positivismo había pensado. Ésta es la vía seguida por el ataque más relevante de entre los emprendidos contra el positivismo jurídico en las últimas décadas. Me refiero obviamente a la teoría de Ronald Dworkin. Según Dworkin, el derecho se compone de una serie de normas reconocibles por el positivismo jurídico y de otras, los principios, ignorados por éste, pero válidos por su corrección moral y que también vinculan a los jueces en su actividad jurisdiccional.

A juicio de Alexy, la teoría de Dworkin supone un avance, porque enriquece el esquema positivista de reglas con una serie de principios. Sin embargo, el profesor alemán no lo considera un avance suficiente. La superación del esquema dworkiniano pasa en la teoría de Alexy por la distinción en el derecho de un lado pasivo y un lado activo. El lado pasivo del derecho está compuesto por una serie de normas (reglas positivistas y principios dworkinianos). El lado activo del derecho está integrado por procedimientos $^{70}$. De acuerdo con Alexy, el derecho debe ser contemplado como un sistema de procedimientos argumentativos y no meramente como un conjunto estático de normas. El derecho debe ser estudiado desde su lado activo y no sólo desde su lado pasivo. El resultado es que la teoría del derecho tiende a convertirse en una teoría de la argumentación jurídica. Esto comporta una consecuencia importante: si el derecho tiende a ser contemplado como una teoría de la argumentación jurídica y de acuerdo con TCE3 la teoría de la argumentación jurídica tiende a convertirse en una teoría de la argumentación moral, entonces el derecho tiende a aproximarse a una forma de razonamiento moral. Éste es precisamente el itinerario que parece describir la argumentación antipositivista implícita en la TCE.

Sin embargo, este planteamiento presenta algunos inconvenientes. Con carácter previo hay que señalar que es dudoso que la teoría de Dworkin no se sitúe en el lado activo al elaborar su teoría del derecho. La carga argumentativa que incorporan los principios dworkinianos y la concepción interpretativa del derecho que sostiene Dworkin en Law's Empire ${ }^{71}$, vinculando el derecho a la soundest theory of law, parecen indicar que también el autor norteamericano incurre en la confusión de teoría de las fuentes y teo-

${ }^{70}$ Vide Alexy, R., «La idea de una teoría procesal de la argumentación jurídica», trad. de Carlos de Santiago, en Garzón Valdés, E. (comp.), Derecho y filosofía, Alfa, Barcelona, 1985, págs. 43-57.

${ }^{71}$ Vide Dworkin, R., El imperio de la justicia, trad. de Claudia Ferrari, Gedisa, Barcelona, 1992. 
ría de la argumentación, teoría del derecho y teoría de la adjudicación, como acertadamente denuncia $\operatorname{Raz}^{12}$.

Éste es un problema que Kelsen considera ${ }^{73}$ al analizar la teoría de Esser y también la de Pound ${ }^{74}$. Esser sostuvo que ciertos principios extrasistemáticos que se hallan en la base de algunas normas también forman parte proprio vigore del derecho. Kelsen opone a este planteamiento un argumento de «economía conceptual»: es necesario delimitar el derecho frente al resto de elementos que intervienen en una decisión judicial; de lo contrario, el concepto de derecho se expandiría tanto que llegaría a perder su significado, pues cualquier norma podría llegar a a formar parte del sistema jurídico.

Sin embargo, no sólo el concepto de derecho sale perjudicado por esta confusión. La propia función judicial queda desvirtuada. Si todas las normas que figuran en la argumentación de un juez deben ser consideradas parte del derecho, entonces la propia vinculación del juez al derecho dejaría de existir. Se produciría una situación semejante a la célebre que relata Platón en el Eutifrón ${ }^{75}$ : si todo lo que el juez aplica es derecho por el hecho de aplicarlo, entonces el juez no está vinculado por derecho alguno (y ésta es una consecuencia que Alexy difícilmente aceptaría $\left.{ }^{76}\right)$.

Para comprender la cuestión adecuadamente, la teoría de Bulygin ${ }^{77}$ resulta una vez más particularmente esclarecedora. El profesor argentino distingue entre pertenencia y aplicabilidad. Una norma válida es una norma que pertenece al derecho. Una norma aplicable es aquélla susceptible de aplicación por los jueces. Normalmente las normas válidas son aplicables y las normas son aplicables en cuanto válidas. Sin embargo, esto no siempre es así. En ocasiones, se aplican normas que no pertenecen al sistema jurídico y en tales casos dejan de ser aplicables normas válidas relevantes para el caso. Esta situación tiene lugar, por ejemplo, cuando se aplican normas ex-

${ }^{72}$ Raz, J., «The Problem about the Nature of Law», en University of Western Ontario Law Review, vol. 21, nº 2 (1983), págs. 203-218, aquí pág. 211.

${ }^{73}$ Aunque Raz («The Problem about the Nature of Law», op. cit., pág. 210) afirma que Kelsen «no tiene tal explicación».

74 Vide Kelsen, H., Teoría general de las normas, trad. de Hugo Carlos Delory Jacobs, Trillas, México, 1994, cap. 28 y págs. 302-303, nota 80.

${ }^{75}$ En ese diálogo dice Sócrates: «...pero reflexiona sobre esto: ¿acaso lo piadoso es amado por los dioses porque es piadoso o es piadoso porque los dioses lo aman?» (Platón, Eutifrón, 10a, cito por el texto traducido, seleccionado y comentado por García Máynez, E., Teorías sobre la justicia en los diálogos de Platón, vol. I, UNAM, México, 1981, págs. 55 ss. y 211).

${ }^{76}$ Vide TAJ, pág. 312, donde Alexy censura la infravaloración de la vinculación a la ley, la dogmática jurídica y el precedente por parte de la tópica.

77 Vide Bulygin, E., «Tiempo y validez», en Alchourrón, C.E. y Bulygin, E., Análisis lógico y derecho, Centro de Estudios Constitucionales, Madrid, 1991, págs. 195-214. 
tranjeras según prescribe alguna norma de conflicto de derecho internacional privado o cuando se aplica derecho histórico de acuerdo con una disposición transitoria. Esto demuestra que no toda norma aplicable es válida.

El esquema es perfectamente trasladable al problema que nos ocupa. Ciertas normas morales y otros estándares que forman parte de la justificación explícita y, en su caso, de la justificación entimemática de una decisión judicial son aplicables a pesar de que no forman parte necesariamente del derecho. Cabría entonces preguntarse de dónde obtienen su aplicabilidad. Las normas extranjeras se aplican sobre la base de una norma válida de derecho internacional privado y el derecho histórico sobre la de una disposición transitoria válida. En realidad, han existido diversos medios para fundar la aplicabilidad de estándares morales extrajurídicos. La forma más manifiesta consiste en el art. 1.2 del código civil suizo ${ }^{78}$, que autoriza al juez a portarse como si fuera un legislador, pero en otros ordenamientos se han ensayado fórmulas más sutiles que tienden a disimular el creacionismo judicial: así las referencias a las buenas costumbres, al orden público, a la diligencia del buen padre de familia, ciertos principios constitucionales, etc. Todas estas «fuentes de discreción», por usar una expresión de Raz ${ }^{79}$, ofrecen una cobertura jurídica a la aplicabilidad de ciertos estándares morales y en los casos difíciles suponen una guía para que el juez desarrolle una teoría de la argumentacion jurídica.

La noción de aplicabilidad permite dar una explicación satisfactoria al problema de la «riqueza del output» y supone una alternativa sólida a la visión no positivista del derecho y a la concepción de la argumentación jurídica según TCE3. Sin embargo, la noción de aplicabilidad no ha concitado la atención que quizá merecería por su versatilidad ${ }^{80}$. Esta versatilidad sí ha sido especialmente puesta de relieve por José Juan Moreso, quien destaca la capacidad de la noción de aplicabilidad para explicar el papel en el sistema jurídico de las normas consuetudinarias, los estándares de moralidad, las normas irregulares ${ }^{81}$ (por ejemplo las inconstitucionales) y las que denomi-

${ }^{78}$ Sobre las implicaciones de la teoría de Dworkin en relación con este precepto del ordenamiento jurídico helvético, vide Strolz, M.M., Ronald Dworkin's These der Rechte im Vergleich zur gesetzgeberischen Methode nach Art. 1 Abs. 2 und 3 ZGB, Schulthess, Zurich, 1991.

${ }^{79}$ Vide Raz, J., «Legal Principles and the Limits of the Law», op. cit., págs. 75-76.

${ }^{80}$ En este sentido, Daniel Mendonça (voz «Aplicación del derecho» en Garzón Valdés, E. y Laporta, F.J. (eds.), vol. II de la Enciclopedia Iberoamericana de Filosofía, El derecho y la justicia, Trotta/CSIC/BOE, Madrid, 1996, págs. 267-282, aquí pág. 279) ha señalado que el par de conceptos aplicabilidad-aplicación «no ha sido objeto de suficiente análisis por parte de los teóricos del derecho, salvo importantes excepciones» (Mendonça cita algunos trabajos de Ross, Bulygin, Moreso y Navarro).

${ }^{81}$ Sobre la distinción entre validez y aplicabilidad en el caso de las normas irregulares y especialmente en relación con la visión del problema por parte de la dogmática, vide en este 
na «normas receptadas» (normas preconstitucionales que obtienen aplicación en el nuevo orden jurídico) ${ }^{82}$.

Ahora bien, si la explicación que nos proporciona la noción de aplicabilidad al problema de la riqueza del output parece bastante razonable, ¿cuál es la razón de la fortuna de la alternativa no positivista? El origen de la confusión de pertenencia y aplicabilidad es la adopción del punto de vista interno, el punto de vista del participante para estudiar el derecho. La confusión de pertenencia y aplicabilidad se puede observar claramente en la siguiente definición de fuente, que nos ofrece Aarnio desde un punto de vista típicamente de participante:

«Toda razón que de acuerdo con las reglas generalmente aceptadas por la comunidad jurídica, puede ser usada como base justificadora de la interpretación es fuente del derecho» ${ }^{83}$

Según esta definición, una fuente es una norma aplicable. Ésta es una definición que se ciñe a la idea de fuente que aparentemente sostienen los participantes, singularmente los jueces. Esta perspectiva de análisis explica también la confusión de teoría del derecho y teoría de la argumentación jurídica, pues el derecho se identifica con el conjunto de razones, formalmente válidas o no, que fundamentan una decisión y también explica la confusión de razonamiento jurídico y razonamiento moral, porque, desde la perspectiva del participante, las razones para la acción deben unificarse bajo una razón última de carácter moral. La teoría de la argumentación jurídica, como la teoría de las razones para la acción, conduce la argumentación jurídica al ámbito de deliberación personal, donde no es posible la fragmentación del discurso práctico y de ahí deriva la unidad del discurso práctico, pero esto tiene lugar bajo el presupuesto de la superioridad del punto de vista interno, del punto de vista del participante para analizar el derecho. Cuando adoptamos el punto de vista externo, que rebasa el ámbito de la deliberación personal, observamos que en la realidad la fragmentación del discurso práctico no sólo es posible, sino frecuente.

Estas últimas consideraciones determinan una importante particularidad en los estándares morales respecto de otras normas inválidas pero aplicables. Mientras que desde un punto de vista interno, las normas extranjeras, derogadas o «receptadas» son consideradas extrajurídicas, los estándares

mismo volumen el trabajo de Pérez Treviño, J.L., «Validez, aplicabilidad y nulidad. Un análisis comparativo de la teoría del derecho y la dogmática jurídica».

${ }_{82}$ Moreso, J.J., La indeterminación del derecho y la interpretación de la Constitución, op. cit., pags. 151 ss. Me he ocupado de esta obra en «Una vigilia con Moreso. Algunas notas a propósito de La indeterminación del derecho y la interpretación de la Constitución», en Anuario de Filosofía del Derecho, ${ }^{\circ}$ XV (1998).

${ }^{83}$ Aarnio, A., Lo racional como razonable, op. cit., pág. 123. 
morales son contemplados como parte del sistema jurídico. El no positivismo ha creado de este modo una asimetría en el conjunto de normas inválidas pero aplicables, mediante la confusión de normas jurídicas y normas morales aplicables en los procesos argumentativos de los participantes, que se rigen por la idea de TCE3.

En suma es necesario trazar los límites del derecho frente a órdenes normativos como la moral y es necesario distinguir la pertenencia de las normas a un sistema jurídico de su aplicabilidad. Que el derecho presente límites no significa que no sea abierto, en el sentido de que permite la aplicabilidad de normas ajenas al sistema jurídico. La aplicabilidad de estándares morales constituye un caso especial de aplicabilidad general en el derecho.

\section{Conclusión}

La tesis del caso especial, núcleo de la teoría de la argumentación jurídica, es ambigua y por ello puede ser interpretada de modos diversos. En este trabajo he tomado como central la version de la tesis del caso especial como una tesis descriptiva que vincula el razonamiento jurídico al razonamiento moral crítico y que reproduce el punto de vista de los participantes, según el cual los jueces «hacen justicia según derecho» cuando ejercen su labor jurisdiccional.

Ahora bien, si el razonamiento jurídico se aproxima al razonamiento moral crítico y la teoría del derecho se convierte en una teoría de la argumentación jurídica, entonces el resultado es una teoría del derecho argumentativa y antipositivista. Estos rasgos confluyen en dos de los ataques más importantes al positivismo jurídico de las últimas décadas: la teoría «interpretativa» del derecho de Dworkin y la teoría del derecho basada en su «lado activo» de Alexy.

La dimensión antipositivista de estas teorías presenta problemas desde un metadiscurso analítico y un metadiscurso normativo. La dimensión argumentativa genera la disolución del concepto de derecho y de la función judicial y se basa en la confusión de las nociones de pertenencia y aplicabilidad, causada por la adopción de la perspectiva interna, del participante, que estas teorías adoptan. 